\title{
Who Benefits And Who Loses From The Regionalization Of World Trade?
}

Richard P. Castanias, (Email: prcastanias@ucdavis.edu), University of California, Davis Yamuna Yelamanchi, (Email: yyelamanchi@ucdavis.edu), University of California, Davis

\begin{abstract}
As regional blocs evolve, developing countries within blocs are prime beneficiaries. Trade between developed countries in different blocs falls relative to theoretical predictions. Many developing countries outside major blocs are the losers. The primary factor driving evolving trade patterns is the lowering of barriers to trade (however defined). As economic integration progresses, a trade zone may evolve into a common market, economic union, or monetary union, facilitating the lowering of trade and growth-inhibiting frictions. Furthermore, barriers to trade will continue to decline within a trade zone faster than between trade zones, but the benefits of economic integration will not be equally shared across all nations in a zone. Policy implications and directions for future research are then discussed.
\end{abstract}

\section{Introduction}

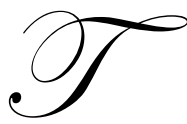

his paper examines the evolution of regional trade blocs in recent decades. There is ample evidence to support the now widely-held view that such trade blocs exist and are continuing to evolve. We find evidence, as has been prophesied for many decades now, that the blocs are centering on Europe and North America, and to a more limited degree on East Asia. The evolution of these blocs is not uniform, however, around the three principal regions. Those countries most closely oriented toward the principal regional blocs appear to be the main beneficiaries of regionalization - as measured by increased trade and income growth. We find that many countries are increasingly focused on one bloc.

The orientation of the trade of the rest of the world is also toward the three principal blocs, but with often mixed and occasionally less promising results. Some countries, for example Mexico in North America and those countries on the eastern periphery of Europe, are clearly caught in the tide of trade-pulled economic growth. Many countries "outside" the three regions are in danger of being left out of the game.

The paper is organized as follows: Section 2 discusses the prevailing theories of regional trade blocs. Section 3 discusses the hypotheses and the model used here to estimate a benchmark to measure which regions and countries are trading more (or less) than expected, and with which to document changing trends in trade. The model used is the augmented gravity model. Section 4 presents the data and the estimation methods used here, and discusses relevant empirical issues. Section 5 presents the results. Section 6 discusses extensions of the paper, including the link between trade and economic growth. Section 7 concludes the paper.

\section{Trade blocs}

The last two decades has seen formal regional trade arrangements strengthening in almost all parts of the world. Very few countries have been left out of some agreement, even if only a local Free Trade agreement (FTA). The European Union (EU) has recently admitted 10 new nations. North American Free Trade Agreement (NAFTA) has continued to develop and lower trade barriers between Mexico, Canada, and the United States. Asia-Pacific Economic Cooperation group (APEC) continues to consolidate. South American countries continue to try to make MERCOSUR work. Free Trade agreements have been signed by numerous other countries. And the list goes on. 
Most will agree that trade agreements and unions are evolving and deepening at an accelerating rate. Clearly the evolution of trade agreements is occurring on a regional basis. There is less agreement as to whether this evolution of world trade is leading to regional trade blocs, and whether such blocs, should they actually exist, are evidence of efficiency enhancing "globalization" or of trade diverting "regionalization". 2, [fn reference to the debate on enhancing vs. diverting trade.]

\subsection{Regional trade blocs really exist}

Do regional trade blocs actually exist? There is growing consensus and mixed evidence that they do. The data from the Worldbank tables on trading blocs suggests that trade in Europe and North America are growing at the expense of interregional trade. Others, Rugman and Moore (2001) for example, argue that more and more business activity by large firms takes place in regional blocks. They conclude that "...(t)here is not a trend toward globalization, but strong evidence of the hardening of the triad blocs." Sapir (1997) found that increased integration within the EU has led to lower imports from non-member European countries.

However, not all agree that the world is heading toward a "triadized" trade structure or whether such a structure necessarily implies inefficient "regionalization". Poon (2000) uses spatial organizing methods to show that investment intensity patterns do not currently conform to any bloc-like formation, but exhibit instead, globally diffused network regions. He asserts that "...despite the near ubiquitous use of the idea of a triadized world, it remains a somewhat normative assertion, the empirical existence of which has yet to be demonstrated."

Similarly, we have Bhagwati's (1998) even more upbeat assertion that “...the outward orientation in trade was not confined to regional trade. East Asia took the whole world as its destination." We argue here that there additional evidence that world trade is regionalizing on the margin, especially in Europe and North America. On the other hand, we find some support for Bhagwati's views on East Asia (also applicable, we think, to Chile and India, two another evolving world traders.)

\subsection{The "New Theory of Trade."}

Growth of trade is, by all theories of trade, a natural bi-product of economic growth (absent punitive barriers). The upbeat view of regional trade agreements is that trade agreements contribute to the globalization of the world and to greater access to free trade for all concerned. A more pessimistic view is that regional trade agreements are trade diverting and welfare decreasing for many, including countries that are members of the regional agreements. Yet a more negative perspective is that those countries which cannot arrange membership in a regional trade agreement will lose even more. One can add to the pessimistic side of the argument the fears that many will succumb to the increasing temptation to impose additional barriers to trade from outside the membership.

Another view of the evolution of regional trade blocs is that they are less the children of political agreement than perhaps the inevitable consequences of economic progress. Proponents of this view might say that trade agreements that develop on a regional basis are a natural phenomenon, driven by the success of previous trade and economic progress. One might call this the "natural trade bloc" hypothesis. Pursuit of newly identified economic opportunities as the "trade playing field" becomes more homogenous within zones creates a force to lower trade inhibiting barriers even farther, and formalized trade agreements are a way to do that. This is not to say that trade agreements and unions are not value enhancing, but rather that they are perhaps endogenous. In support of this hypothesis is the ample evidence that trade in most regions and between most FTA country pairs increases sufficiently in advance of the formal agreements so as to make the argument of causality (or even of anticipation) difficult to make.

We deliberately avoid a discussion of causality or necessity - does fertile ground cause farms or do farmers (crops, whatever) create fertile ground? We use the "natural trade" hypothesis as a counter hypothesis to the seemingly pervasive idea that governments and government agreements are necessary preconditions to increasing world trade - not at all to downplay the potential for governments to fix market failure or to "unblock" barriers to free trade, or even the harm that governments can do to markets that otherwise would function freely. One 
characterization of this hypothesis is that multinational corporations are a factor in pushing the evolution of trade zones motivated by economic (profit-seeking) rather than political goals.

Following the "natural trade hypothesis," trade zones (loosely defined for now) create lower-cost economic opportunity, and that economic agents will respond by exploiting these opportunities. The end result is economic growth, and eventually higher profits, higher incomes and more jobs, etc.

A trade zone uncovers these opportunities by lowering barriers to trade and costs of doing business within the zone. Many of the barriers to trade and costs are nonpecuniary (non tariff, non tax, etc.). Some of those "costs" are related to infrastructure, management techniques, and business organization. Others are related to government and private sector attitudes concerning interregional trade, intraregional trade, and perhaps even simply attitudes concerning "business", making profits, job security, the social welfare net, etc. Yet others relate to risks that economic agents must face, such as exchange rate risk and contract enforcement risk.

We speculate that as business expands within a trade zone, the incentives to "homogenize" the business environment grow and, if circumstances permit, the trade zone "deepens" to become more than just a tariff agreement. The European Union is a good example. The best and most extreme example of a deepened trade bloc is still the 50 United States. As trade zones deepen, business opportunity continues to increase, new exploitable comparative advantages emerge and are pursued, and the members of the trade zone experience growth.

A further assertion is that most of the major forces and effects are endogenous. It doesn't matter whether businessmen, politicians, and the general public be aware of the process; it will happen anyway barring significant exogenous intervention. Exogenous intervention is possible but not really likely at any point in time.

\section{The hypotheses to be tested here}

We conjecture that as major trade blocs evolve, developing countries within a bloc are the prime beneficiaries. Trade between developed countries in different blocs will fall relative to theoretical predictions. Many developing countries outside major blocs are the losers.

The primary factor driving evolving trade patterns is the lowering of barriers to trade (however defined). As economic integration progresses, a trade zone may evolve into a common market, economic union, or monetary union, facilitating the lowering of trade and growth-inhibiting frictions. Furthermore, barriers to trade will continue to decline within a trade zone faster than between trade zones, but the benefits of economic integration will not be equally shared across all nations in a zone. Our model predicts and we find empirical evidence consistent with the following:

H1. Trade between major trading regions (North America, Europe, etc.) will decline relative to theoretical predictions as nations within evolving zones accelerate the pursuit of increasingly profitable business opportunities within their home regions.

H2. Within trade regions, trade from less developed countries to developed countries will increase relative to theoretical predictions.

H3. Trade between developed countries will increase relative to theoretical predictions, but less than that from developing countries to developed countries.

H4. Some regions outside major trade zones will be net losers as trade is diverted toward the emerging peripheries of major trading zones. 


\section{The model}

Rather than look at absolute trade, we choose to estimate a model of the determination of trade so that we can focus on changes in export that are not easily explained by the growth in the level of economic activity. We base our tests on the fixed effects on the bilateral trade augmented gravity model similar to that of Cheng and Wall [fn]

$\operatorname{LnX}_{\mathrm{ijt}}=\beta_{0}+\beta_{\mathrm{t}} \mathrm{t}+\beta_{\mathrm{ij}}+\beta_{1} \ln \mathrm{Y}_{\mathrm{it}}+\beta_{2} \ln \mathrm{Y}_{\mathrm{jt}}+\beta_{3} \ln \mathrm{Pop}_{\mathrm{it}}+\beta_{4} \operatorname{lnPop}_{\mathrm{jt}}+$ Region $\mathrm{j}+\varepsilon_{\mathrm{ijt}}$

All "fixed effects" variables are left out of the regression: e.g. $\beta_{\mathrm{ij}}$ now captures the effects of $\operatorname{lnDist} \mathrm{t}_{\mathrm{ij}}$; Cont $_{\mathrm{ij}}$; lang $_{\mathrm{ij}}$

\subsection{The dependent variable, Trade}

The dependent variable $X_{\mathrm{ijt}}$ is $\mathrm{TRADE}_{\mathrm{ij}}$, the value of bilateral exports converted into millions of U.S. dollars. The log specification allows the coefficients to be interpreted as elasticities but omits country pairs where measured bilateral trade is zero. This is not desirable in that zero-trade observations contain information about tradeinhibiting barriers. We adopt the solution of expressing the dependent variable as $\operatorname{Ln}\left(1+\mathrm{X}_{\mathrm{ij}}\right)$. For values of trade that are very large, $\operatorname{Ln}\left(1+X_{\mathrm{ij}}\right)$ approximately equals $\operatorname{Ln}\left(\mathrm{X}_{\mathrm{ij}}\right)$, preserving the log relationship, while for smaller bilateral trade values $\operatorname{Ln}\left(1+\mathrm{X}_{\mathrm{ij}}\right)$, approximately equals $\mathrm{Ln}\left(\mathrm{X}_{\mathrm{ij}}\right)$, a semilog Tobit relationship. The model (R1) above can be estimated by Pooled OLS.

We use two samples of bilateral trade data here. The first is from Feenstra World Trade Flows, annual bilateral trade data for up to 253 countries 1992 - 1997. This data is used initially all studies. The second annual bilateral trade data set if from the OECD International Trade by Commodity Statistics, and runs from 1960 through 2002. The OECD data includes exports and imports from 29 OECD and other major countries and exports to OECD countries from up to 264 different countries. Most results reported here use the OECD data to take advantage of the longer period of coverage and more recent data. It is important to note that the OECD data set does not include imports into most of the 264 partner countries from other non-OECD countries, although the bilateral trade coverage provided by the 29 OECD countries accounts for $84 \%$ of exports from and $99 \%$ of the imports to OECD countries.

\subsection{GDP and Population}

The GDP and population data were from the World Bank World Development Indictors database. We gathered data for all bilateral trades between 30 (29?) OECD and selected non-OECD countries, FN1 and imports into these countries from (up to) 264 partner countries, for the years 1960 through 2002.

\subsection{Time dummies}

We might, as others have, take the time dummies as indicators of the extent of "globalization", which we define as the purported common trend towards greater real trading volumes, independent of the sizes of the economies. Perhaps surprisingly, we find that the coefficients on the time dummies do not indicate a trend towards globalization.

\subsection{Regional Indicators.}

Our definition of a trade bloc is that a disproportional percentage of the exports of the countries located in a region go to other countries in the same region, and that the percentage is increasing over time.

The most common and straightforward method for estimating the effects of integration in a gravity model is to include dummy variables for each region or collection of countries in place during the sample period.

A regional dummy takes the value of 1 for an observation for which the exporting country or region is a member of region $i$ and the importing country or region is in region $j$. The expectation is that the coefficients on these dummies are positive if the exporting country trades more with the limporting country than predicted by their 
incomes, population, and other model factors. If trading blocs explain none of the bilateral trade between countries and regions, then the base in variables in the gravity equation, GDP, per-capita income, bilateral distance, and other factors such as common borders and languages, should incorporate all the explanatory power. Then a dummy variable representing interregional trade should be insignificant. We also look at intraregional trade for most regions. If exporting and importing country pairs are in the same region, and intraregional trade is enhanced (however so), then the dummy coefficient should estimate to be greater than zero.

We include up to nine such dummy variables in our model, one for each of four groups of countries in the European region, one for North American, South America, Oceania, Africa, and one for Asia. The regions North America, East/South East Asia, Oceania, South Asia, South America, and Africa. Include all countries geographically in those continents.

The four regional groups for the Europe are laid out so as to allow us to study the progression over time of trade patterns within Greater Europe and its periphery. The three countries France, Germany, and The UK, designated the "trading core" of pre EU Europe, are assigned to region Euro1. The designations Euro2 through Euro4 are progressively more on the perimeter of Greater Europe. The region Euro2 includes the 15 other EU and EFTA countries. Euro3 includes most recent EU candidate countries plus other Eastern European countries, and Mediterranean countries that trade historically with Europe. Euro4 includes 10 countries in the Middle East, Africa and Eastern Europe that are most distant economically from the core countries of Europe.

\subsection{Distance, contiguity and common language}

Distance in not suggested as a factor by the theory that underlays the model. It is rationalized as a proxy for trade barriers that are increasing in distance, such as transactions costs. It might perhaps be better to directly measure such barriers, but his has proven to be difficult in empirical trade studies, and so distance is a commonly used proxy. By the same logic, a dummy for common borders is often included in empirical gravity models, and can be thought to approximate a fixed cost associated with barriers to trade. Common borders and distance, taken together, tend to have significant explanatory power in gravity models.

Because of the difficulty in determining the appropriate measure of economic distance so as to capture transportation and information costs (see Head and Mayer, 2001), an added benefit of the fixed effects model is that it eliminates the need to include in the regression as separate explanators trade-pair specific factors that are constant over time. Alternatively, we follow the approach of Cheng and Wall and estimate our model as a two-stage process, with the second stage testing for the significance of distance and other fixed, common explanators in the second stage. Our fixed-effects approach, discussed below, eliminates the need to include a distance variable, as it controls for all variables that do not change over time.

Common language and common border data come from the geo-cepi datafile. Whatever was not in that file was figured out and filled in using hand-collected. The languages of Sweden, Norway, and Denmark were combined to "Scandinavian".

\subsection{Heterogeneity bias and Fixed Effects}

In addition to per capita income, population, distance, there are historical, cultural, ethnic, political, or geographic factors that affect the level of trade between two countries. These factors are difficult to identify, much less model. If these factors are omitted from the model but are correlated with the gravity variables (GDP, population, distance), the model will suffer from heterogeneity bias. One solution suggested and analyzed by Cheng and Wall (2003) is to introduce fixed-effects into the gravity equation.

Fixed effects models allow for unobserved or misspecified factors that simultaneously explain trade volume between two countries and, for example, the probability that the countries will be in the same regional trade. They have also been used by to estimate the trading pair-specific effects of currency unions to estimate the effects of borders on trade; to calculate trade potentials; and to estimate the costs of protection. 
Another advantage of a fixed effects model is that it removes the problem of controlling for contiguity and common language, as these are, like distance, constant (by assumption here) for all trade between any pair of countries.

All of the regressions were run with and without the fixed, effects. This made very little difference to the testing of the hypotheses, and so only first stage of the 2-stage results are reported here. These restrictions do not change the coefficient estimates very much, but, as Cheng and Wall (2003) have show, lead to biased and large residuals, indicating inaccurate in-sample predictions of trade flows.

\subsection{Estimation of the model}

A set of nine pooled regressions are run for exports from each of the regions Euro1, Euro2, Euro3, Euro4, NA, SA, E, to each of the nine regions.

$$
\operatorname{LnX}_{\mathrm{ijt}}=\beta_{0}+\beta_{\mathrm{t}} \mathrm{t}+\beta_{\mathrm{ij}}+\beta_{1} \ln \mathrm{Y}_{\mathrm{it}}+\beta_{2} \ln \mathrm{Y}_{\mathrm{jt}}+\beta_{3} \ln P o p_{\mathrm{it}}+\beta_{4} \operatorname{lnPop}_{\mathrm{jt}}+\text { Region } \mathrm{j}+\varepsilon_{\mathrm{ijt}}
$$

where $i$ is the exporting country or region and $\mathrm{j}$ is an importing region (one of the nine regions identified above.)

Fixed effects were estimated for each bilateral trade pair. As suggested by Mátyás (1998), we tested whether the country-pair effects are random, rather than fixed. A Hausman test easily rejects this.

\section{Results}

The results of estimating our model are reported in Table 3 for the case of exports from the Region Euro 1 (France, Germany, and the UK) to the other nine regions.

The estimated coefficients on the LnGDP and LnPOP variables conform in general with theoretical expectations and the experiences of other researchers. Note that the coefficients on the LnGDP variable tend to be smaller in model where fixed effects are incorporated for each trading pair.

The signs expected for population coefficients are not as unambiguous, and the literature has not tended to find a consistent sign for $\beta 3$ and $\beta_{4} \square$. However, according to Bergstrand (1989), a positive (negative) sign for $\beta_{3}$ $\square$ indicates that exports tend to be labor (capital) intensive, and a negative (positive) sign for $\beta_{4} \square$ indicates that exports tend to be luxury (necessity) goods. Here, $\beta_{4}$ is generally not significant.

When distance is included in the regression, it is highly negatively significant as expected. When the distance effect is in the second stage of a two-stage regression, it is equally highly negatively significant.

The time trend series tends to be variable, depending on the particular regression. An average, the time trends are not significant, and not strongly correlated with the time trends observed in the regional coefficients.

\section{Regional coefficients}

The main test of our four hypotheses is in the interpretation of the estimated regional coefficients. Graphs 1-4 show the trade patterns of countries in and around Europe. We notice increasing trade patters and higher performance relative to what the model predicts for the OECD countries in the core European regions - Euro1 and Euro 2. We also notice that imports into OECD countries for the remaining regions is either negative relative to our model predictions or is on a decreasing/less increasing trends. We can notice the same pattern for the North Americas, E/SE Asia regions in graphs $5 \&$ 7. Notice in graphs 6 and 9, the pull in trade for the South America and South Asia (primarily India) regions due to the affiliation with the North Americas and Core Europe. Graph 8 shows the pull in trade for the Oceania region due to its affiliation with E/SE Asia. Graph 10, Exports from Africa into OECD countries, clearly shows the loss of not associating with any of the three major trade blocs. Graphs 1113 are microscopic views of countries in NAFTA to illustrate hypothesis 2 and 3, which says, while intra-region 
trade is supposed to increase for both the developed and developing countries, the increasing trend in the intraregion trade is much higher for the developing countries (due to opening up their barriers to trade) that the developed countries. Compare the trend increases for US vs. Canada vs. Mexico.
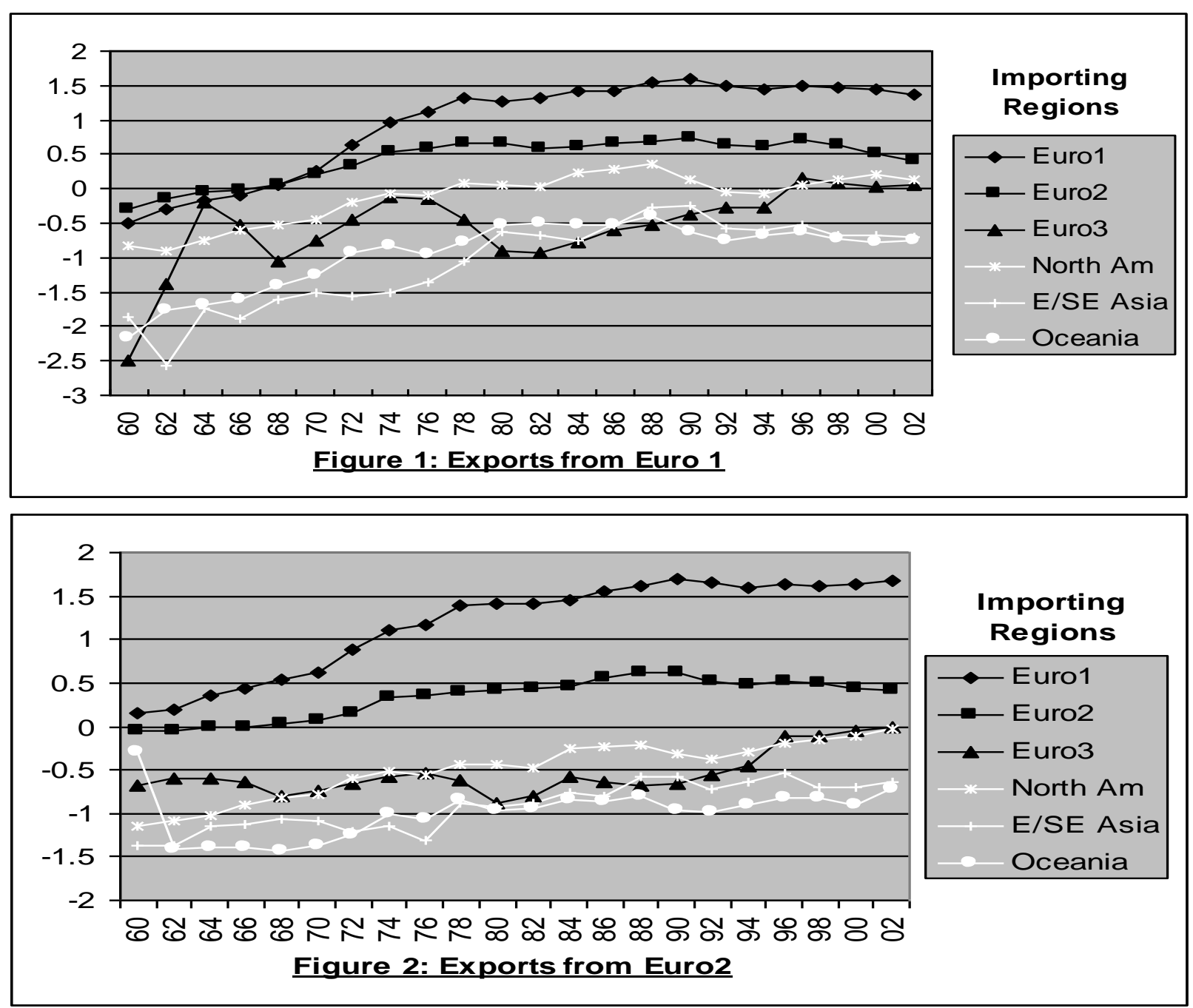

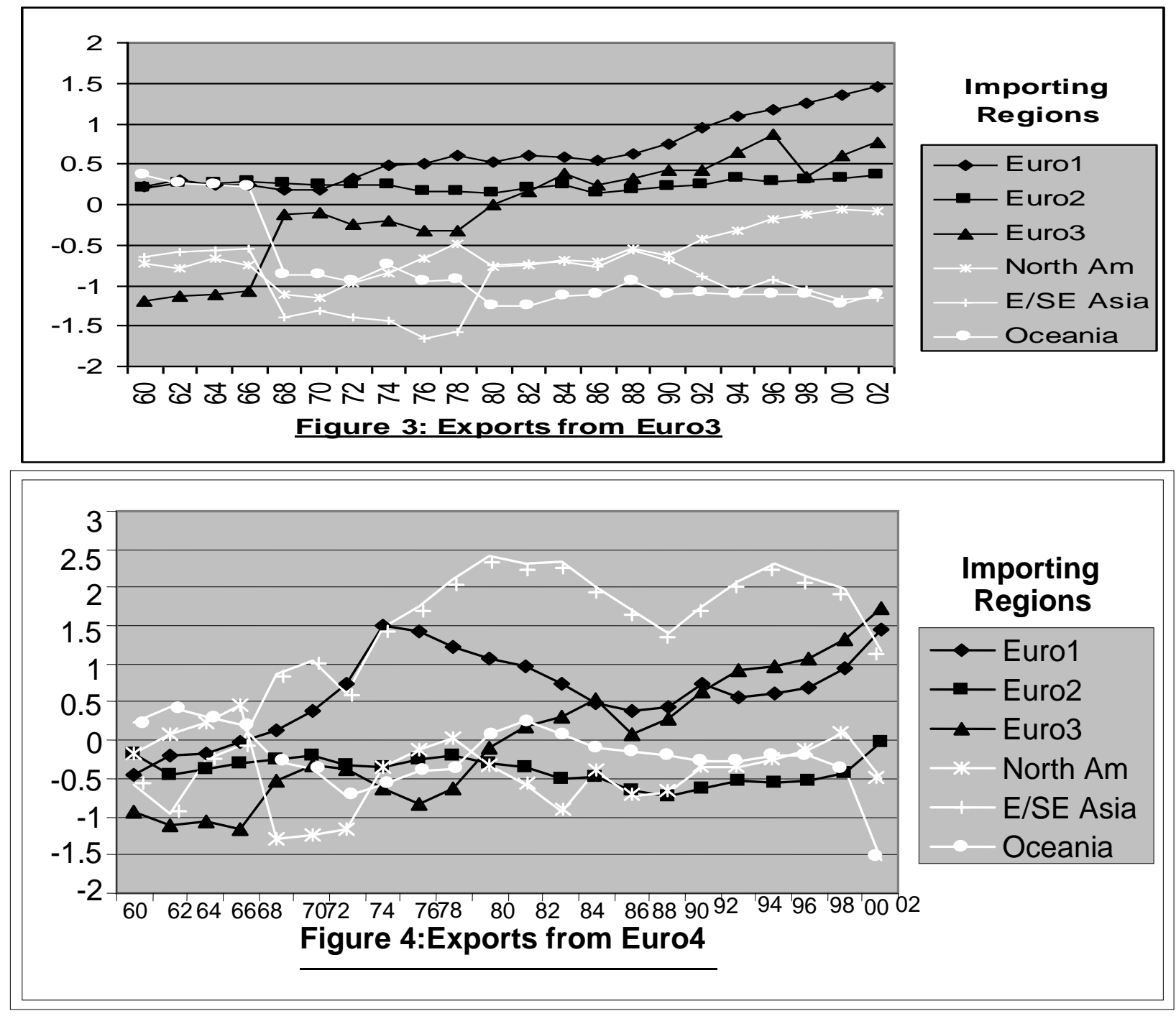

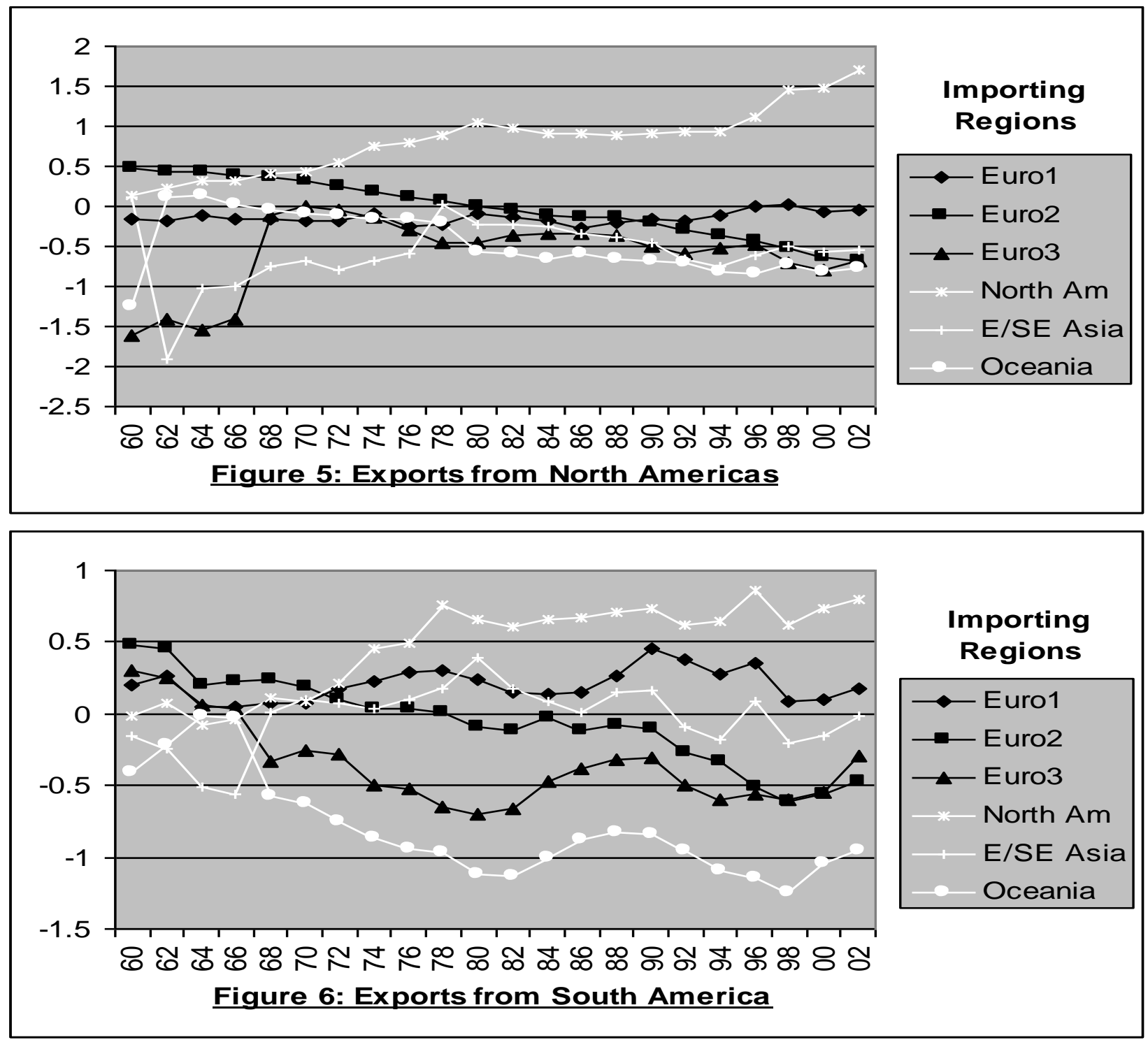

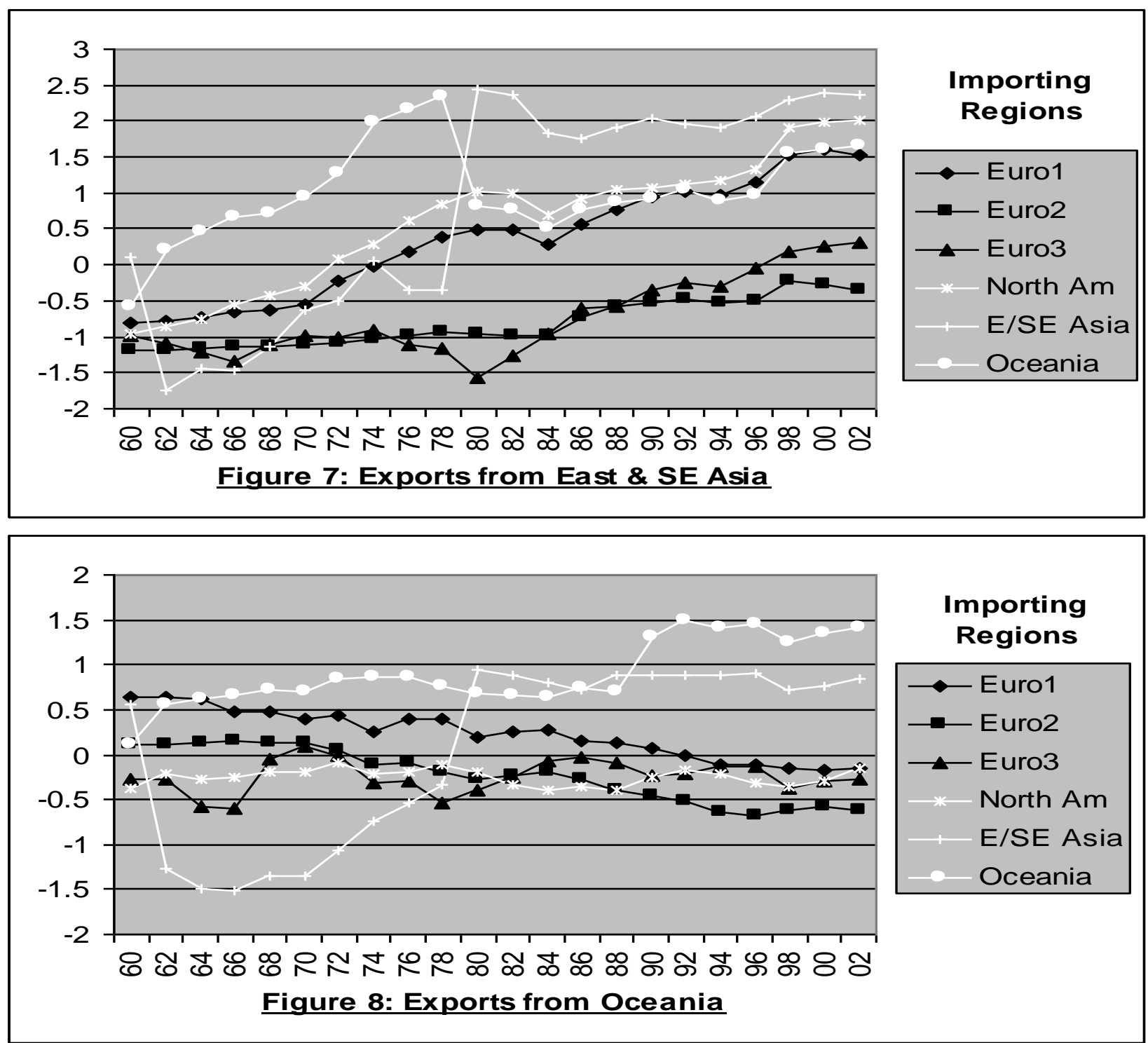

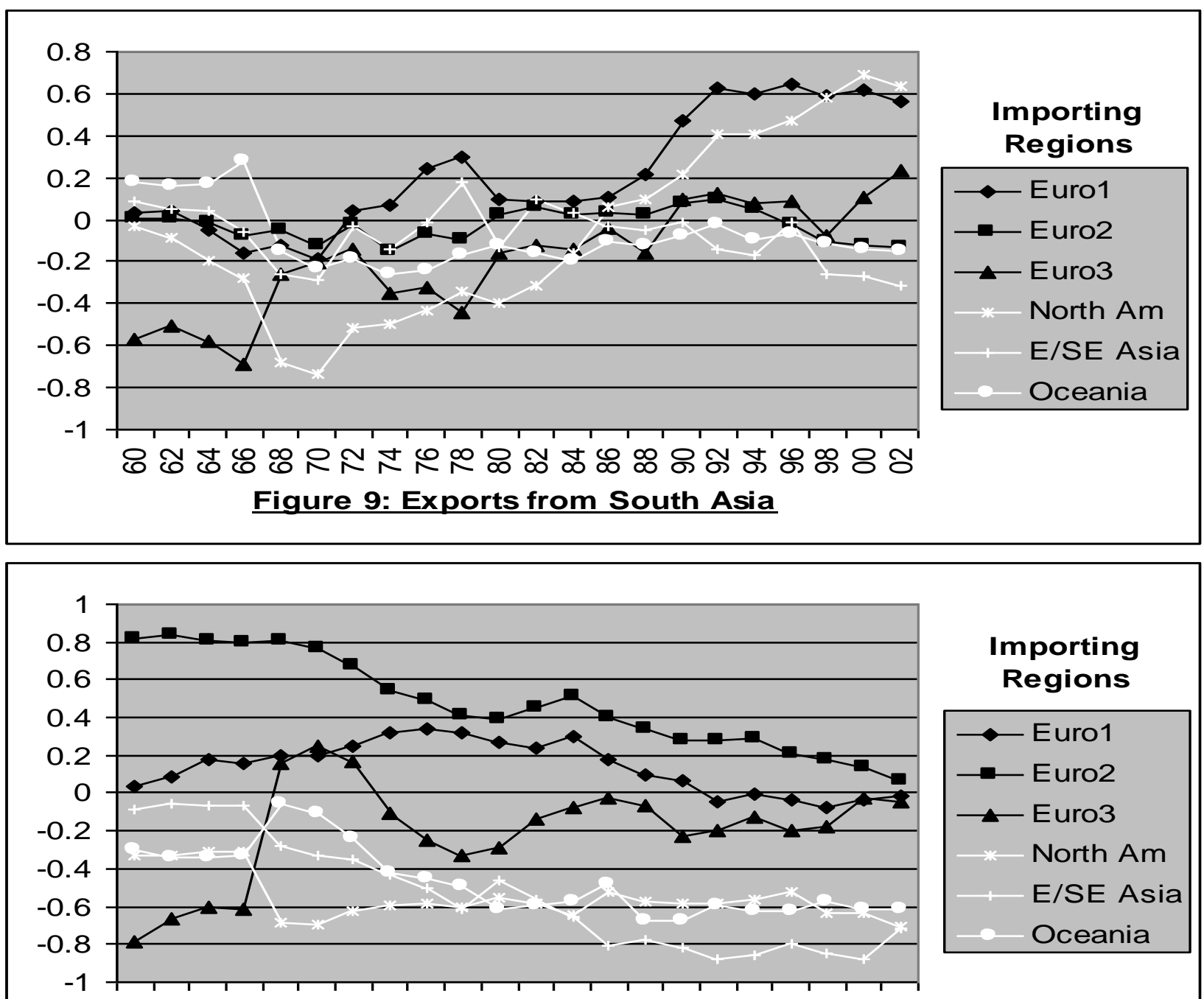

\section{Importing \\ Regions}

8 ש

\section{Figure 10: Exports from Africa}



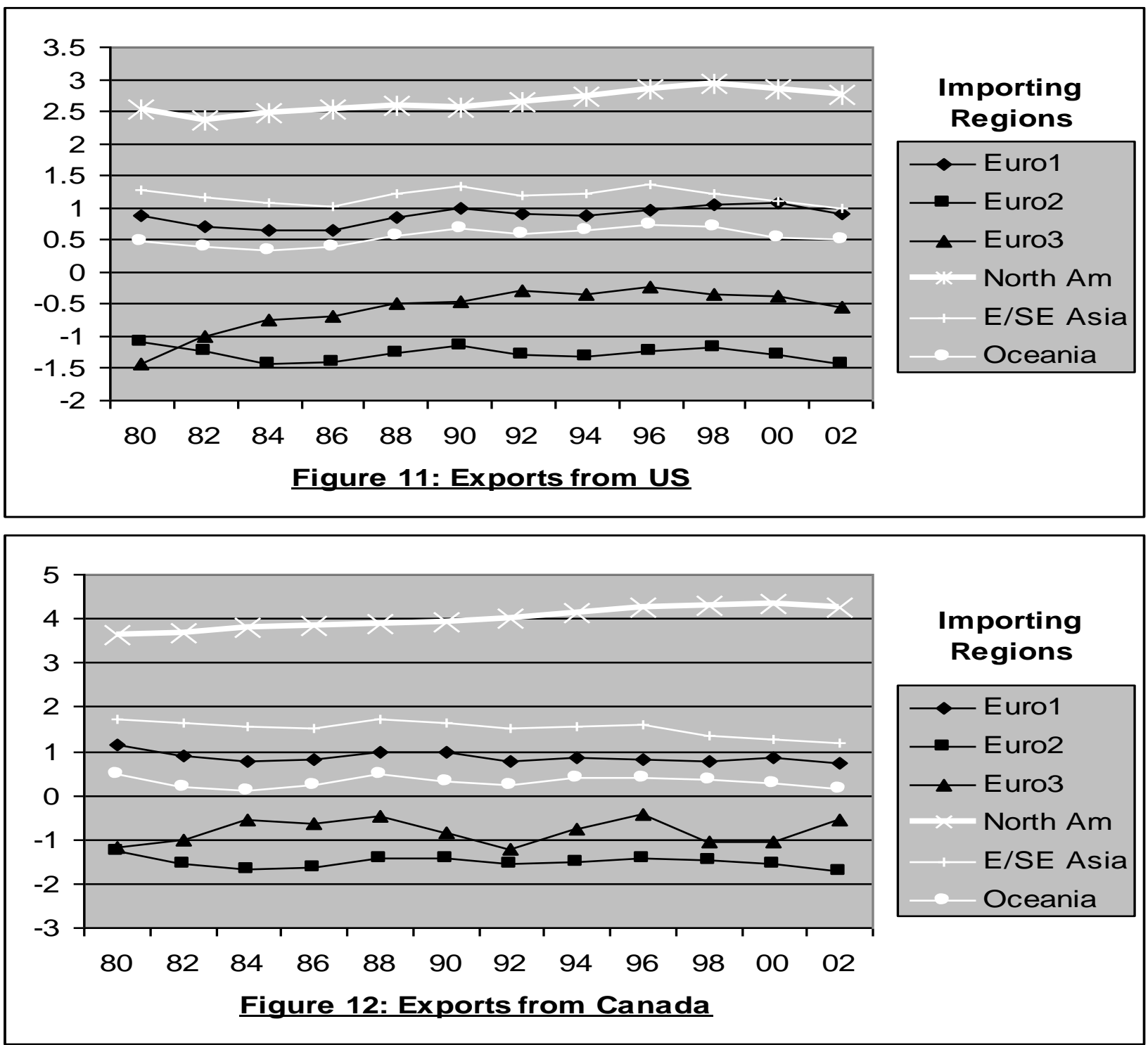


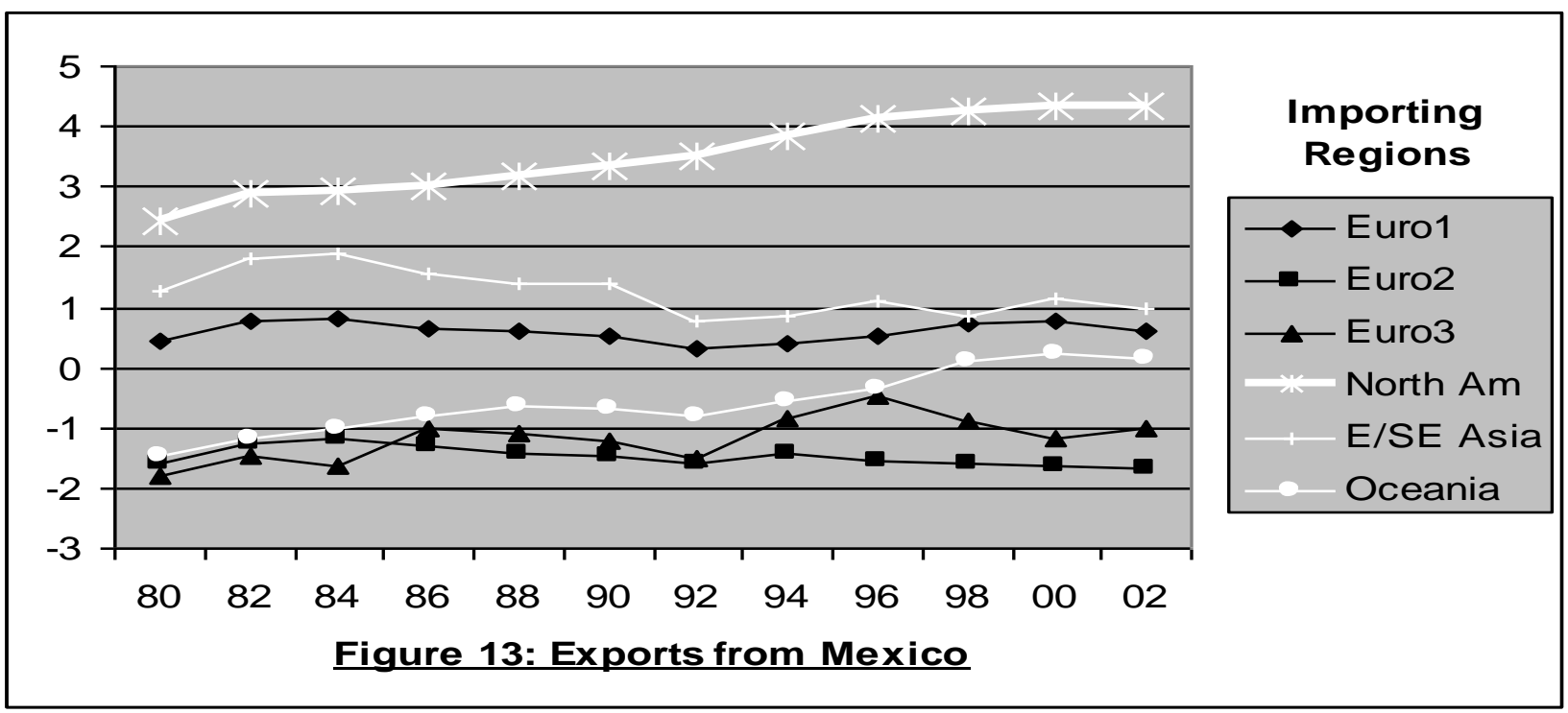

\section{Conclusion}

We find evidence in support of the hypothesis that the world has been gradually and persistently moving toward blocs and the blocs are centering on Europe and North America, and to a more limited degree on East Asia. The evolution of these blocs is not uniform, however, around the three principal regions. Those countries most closely oriented toward the principal regional blocs appear to be the main beneficiaries of regionalization - as measured by increased trade and income growth. We find that many countries are increasingly focused on one bloc.

Some countries, for example Mexico in North America and those countries on the eastern periphery of Europe, are clearly caught in the tide of trade-pulled economic growth. Many countries "outside" the three regions are in danger of being left out of the game.

FN1 [Canada, Mexico, the United States, Australia, Japan, Korea, New Zealand, Austria, Belgium, the Czech Republic, Denmark, Finland, France, Germany, Greece, Hungary, Iceland, Ireland, Italy, Luxembourg, the Netherlands, Norway, Poland, Portugal, Spain, Sweden, Switzerland, Turkey, and the United Kingdom.]

\section{References}

1. Aitken, N. D., 1973, "The Effect of the EEC and EFTA on European Trade: A Temporal Cross- Section Analysis," American Economic Review, 63, 5, 881-892.

2. Anderson, J. E., 1979, “A Theoretical Foundation for the Gravity Equation," American Economic Review, 69, 1, 106116.

3. Bayoumi, T. and B. Eichengreen, 1997, "Is Regionalism Simply a Diversion? Evidence from the Evolution of the EC and EFTA," in T. Ito and A. O. Krueger, Eds., Regionalism versus Multilateral Trade Arrangements, University of Chicago Press.

4. Bergstrand, J. H., 1985, "The Gravity Equation in International Trade: Some Microeconomic Foundations and Empirical Evidence," Review of Economics and Statistics, 67, 474-481.

5. Bergstrand, J. H., 1989, "The Generalized Gravity Equation, Monopolistic Competition, and the Factor- Proportions Theory of International Trade," Review of Economics and Statistics, 71, 143- 153.

6. Bhagwati, J. 1991, The world trading system at risk. New York: Harvester Wheatsheaf.

7. Bhagwati, J. and A. Panagariya (1996). "Regionalism Versus Multilateralism: The Theory of Preferential Trade Agreements: Historical Evolution and Current Trends." The American Economic Review 86(2): 82-87.

8. Bhagwati, Jagdish, 2004, The human face of globalization. 
9. Boisso, D. and M. Ferrantino, 1997, "Economic Distance, Cultural Distance, and Openness in International Trade: Empirical Puzzles," Journal of Economic Integration, 12, 456-484.

10. Brada, J. C. and J. A. Mendez, 1983, "Regional Economic Integration and the Volume of Intra- Regional Trade: A Comparison of Developed and Developing Country Experience," Kyklos, 36, 589-603.

11. Coughlin, C. C. and H. J. Wall, 2002, "NAFTA and the Changing Pattern of State Exports," Papers in Regional Science, forthcoming.

12. Deardorff, A.V., 1984, "Testing Trade Theories and Predicting Trade Flows," in R. W. Jones and P. B. Kenen, Eds., Handbook of International Economics, Vol. I, Elsevier.

13. Deardorff, A.V., 1998, "Determinants of Bilateral Trade: Does Gravity Work in a Neoclassical World?" in J. A. Frankel, Ed., The Regionalization of the World Economy, University of Chicago Press.

14. Egger, P., 2002, "An Econometric View on the Estimation of Gravity Models and the Calculation of Trade Potentials," World Economy, 25, 297-312.

15. Eichengreen, B. and D. A. Irwin, 1998, “The Role of History in Bilateral Trade Flows,” in J. A.

16. Evenett, S. J. and W. Keller, 2002, “On Theories Explaining the Success of the Gravity Equation," Journal of Political Economy, 110, 281-316.

17. Feenstra, R.C., 2000, "World Trade Flows, 1980-1997," Center for International Data, University of California, Davis.

18. Feenstra. R. C., J.A. Markusen, and A.K. Rose, 2000, "Using the Gravity Equation to Differentiate Among Alternative Theories of Trade," Canadian Journal of Economics, 34, forthcoming.

19. Frankel, Ed., The Regionalization of the World Economy, University of Chicago Press.

20. Frankel, J. A. and S. Wei, 1998, "Regionalization of World Trade and Currencies," in J. A.

21. Frankel, J. A., 1997, Regional Trading Blocs, Institute for International Economics.

22. Frankel, J. A., Stein, E. and S. Wei, 1995, "Trading Blocs and the Americas: the Natural, the Unnatural, and the SuperNatural," Journal of Development Economics, 47, 61-95.

23. Frankel, J. A., Stein, E. and S. Wei, 1998, "Continental Trading Blocs: Are they Natural or Supernatural?" in J.A. Frankel, J. A., 1997, Regional Trading Blocs, Institute for International Economics.

24. Glick, R. and A.K. Rose (2002), Does a currency union affect trade? The time series evidence, European Economic Review, 46, 1125-1151.

25. Krueger, Eds., Regionalism versus Multilateral Trade Arrangements, University of Chicago Press.

26. Linnemann, H., 1966, An Econometric Study of International Trade Flows, North-Holland.

27.

28. Mátyás, L., 1998, “The Gravity Model: Some Econometric Considerations,” The World Economy, 21, 397-401.

Mátyás, L., 1997, "Proper Econometric Specification of the Gravity Model," The World Economy, 20, 363-368. Mátyás, L., 1997, "Proper Econometric Specification of the Gravity Model,” The World Economy, 20, 363-368.

30 . O'Loughlin, J. and L. Anselin (1996). "Geo-Economic Competition and Trade Bloc Formation: United States, German and Japanese export, 1968-1992." Economic Geography 72(2): 131-160.

31. Pakko, M.R, and H.J. Wall, 2001, "Reconsidering the Trade-Creating Effects of a Currency Union," Federal Reserve Bank of St. Louis Review, 83, September/October, 37-46.

32. Poon, J. P. (1997). "The Cosmopolitanization of Trade Regions: Global Trends and Implications, 1965-1990." Economic Geography 73(4): 390-404.

33. Poon, J.P.H., Thompson E.R., and Kelly P.F., "Myth of the triad? The geography of trade and investment "blocs"" Transactions of the Institute of British Geographers December 2000, vol. 25, no. 4, pp. 427-444(18).

34. Pöyhönen, P., 1963, “A Tentative Model for the Volume of Trade Between Countries," Weltwirtschaftliches Archiv, 90, 93-100.

35. Reardon, James, Nathan D. Kling, Denny E. McCorkle, Chip Miller, The Formation of Regional Trade Blocs: A Theoretical Perspective Using Game Theory, American Business Review, January, 2002, Vol. 20, No. 1; Pg. 91-99;

36. Rose, A., 2000, “One Money, One Market: The Effect of Common Currencies on Trade.” Economic Policy, 15, 7-46.

37. Rose, A., and R. Glick, 2001, "Does a Currency Union Affect Trade? The Time Series Evidence," NBER Working Paper No. 8396.

38. Rugman, Alan and Karl Moore, The Myths of Globalization. Ivey Business Journal 66:1 (September 2001): 64-68.

39. Sapir (1997)

40. Soloaga, I. and L. A. Winters, 2001, "Regionalism in the Nineties: What Effect on Trade?" The North American Journal of Economics and Finance, 12, 1-29.

41. Tinbergen, J., 1962, Shaping the World Economy - Suggestions for an International Economic Policy, The Twentieth Century Fund.

42. Wall, H.J., 2000, "Gravity-Model Specification and the Effect of the Canada-US Border," Federal Reserve Bank of St. Louis Working Paper No. 2000-024A.

43. Wall, H.J., 1999, "Using the Gravity Model to Estimate the Costs of Protection," Federal Reserve Bank of St. Louis Review, 81, 33-40.

44. Wei, S. J. and J. A. Frankel, 1997, "Open versus Closed Trading Blocs,” in T. Ito and A. 